\title{
SOCIAL MEDIA EDUCATION IN THE ARAB WORLD: REALITY AND CHALLENGES
}

\author{
Elsayed B. Darwish \\ Zayed University, UAE
}

\begin{abstract}
Despite the rapid development of communication technologies which has sparked the creative incorporation of social media into current pedagogical processes, the issue of social media, in the Arab World, has not been subject to extensive pedagogical research, and has not been offered till today as a complete and independent program in Arab media colleges. Moreover, it has not been included as courses in many media programs.

This paper explores the status-quo of integrating social media into Arab media programs, investigates to what extent, it becomes part of their curricula, the attitudes toward social media as an educational tool, the obstacles which hinder offering social media in Arab Universities, either as a program or courses or to be integrated into the conventional media courses. The paper aims at proposing a model of integrating social media into media programs to make the curricula more responsive to changing societal, cultural, workplace values and practices and to prepare students for careers in digital and social media. It assumes that overall student learning can increase when educators incorporate social media into academic course content. It also assumes that social media can be separate and unique courses which should be integrated into the curricula of media programs and it could be a program by itself such as journalism and public relations specializations. The paper analyzed the study plans of several media programs in the Arab world, conducted meta-analysis and interviews with some Arab media faculty to examine the reality and challenges facing social media education in the Arab World.

The paper illustrated that there is a great absence of information about the ongoing experimentations of using different instructional approaches to the curricula that prepare students for technological and cultural shifts in the media industry world in the Arab Universities, the ongoing process for integrating social media into media programs, and how media faculty and students are reacting towards the new paradigms to integrate social media into media education.

The paper stated that the use of social media is not noticeable to some extent, especially in academic matters. Most Arab media colleges are using traditional ways in teaching media courses, without using social media as an educational tool. No Arab media colleges are offering social media as a program by itself, few Arab media faculty are integrating social media into their courses, and there are few studies which dealt with social media as an educational tool. Many indications show that media educators and practitioners' efforts are still far behind the theoretical and practical criteria, on how we can integrate social media into journalism and media programs in the Arab media colleges and media outlets.

The study concluded that despite the growing demand for digitally competent employees in the news media industry, Arab media programs are cautiously integrating social media courses into their curriculum and most students are graduating without being endowed with the required skills to work in social media departments in news organizations or in the government communication entities.

The paper outlined a proposal for initiating social media programs in the Arab Universities, suggesting that the curricula should emphasis on ethics, technical skills, and the potential for career development. The paper recommended of initiating new programs for social media, reconstructing the curricula of the conventional media courses to be taught through social media platforms and to integrate topics related to social media into these courses. The program should deal with the communication, historical, technical, economic, cultural, and legal aspects of social media, in addition to the impacts, and uses of social media in news, media, communication, marketing, public relations, advertising, government communication and how we can measure and analyses its performance digitally.
\end{abstract}

\section{KEYWORDS}

Social Media, Media Education, Arab Media Education 


\section{SOCIAL MEDIA AS AN EDUCATIONAL TOOL BETWEEN THEORY AND PRACTICE}

Social media is becoming popular with students to connect with their peers, businesses, areas of interest and with campus life. It is also becoming ever more popular among instructors, who look to technology to enhance their instructions, peer interactions, to promote collaboration and information, engagement, active learning, facilitate discussion and knowledge transfer between students, thus creating a deeper sense of understanding of course materials.

Studies focusing on pedagogy, learning outcomes, or teaching styles have shown that the use of social media in coursework is linked to higher enthusiasm, engagement, and even grades (Junco, et al., 2011) (Veletsianos, 2012) (Kothari and Hickerson, 2016).

There is little understanding of how social media works in practice and the perceptions of faculty and students towards using social media in media education. There is also a little discussion to date about some practical concerns for educators, when integrating this technology into the learning process and the status quo of its uses and the factors which hinder its expansion in higher education, especially in media education. However, incorporating social media into traditional coursework presents practical and pedagogical challenges (Kothari and Hickerson, 2016).

There is also a noticeable absence of literature that evaluates instructional approaches and related learning outcomes (Bor, 2014). Few studies have proposed concrete study plans for offering social media as a program and guidelines for integrating social media as an educational tool into conventional media courses. In this study, we will examine the status quo of social media education in the Arab media colleges and outline a proposal for offering a program for teaching social media to communication students.

\section{SOCIAL MEDIA IN PROFESSIONAL MEDIA PRACTICE AND EDUCATION}

With the rise of online journalism and newsroom convergence, it is no surprise that contemporary news organizations are seeking employees who are competent to perform in a digital newsroom, and using an array of web-based platforms such as social media sites to report news in a professional manner, not just possessing oral and written communication skills (Bor, 2014), (Auxier, 2012).

Nowadays, media colleges and institutions around the world are exploring ways to meet the news organizations' arising needs by offering digital media and social media in their programs and courses.

An intensive debate is rising among media professionals and educators about embedding social media into journalism and media courses and programs, in a way which lead media graduates to cope with the changing shifts in media industry. The lack of empirical data aside, scholars provide good reasons for incorporating social media into journalism education, beyond the fact that it is increasingly required "in the real world."

Some scholars have attempted to provide justification for integrating a digital curriculum in media programs by analyzing current trends in the news industry (Bor, 2014). They have concluded that demands for skills are constantly changing, and a need for incorporating social media and digital reporting skills into the journalism curriculum and a re-evaluation of media education is needed to meet the digital demand in the news media business.

However, less is known about how journalism and mass communication programs incorporate social media in their coursework. A survey of 323 students and 125 faculty in American universities, found that students' majors and faculty's experience in the industry influenced not only how they evaluated the utility of social media in coursework, but also how they utilized various platforms in classes (Kothari and Hickerson, (2016).in study conducted on Arab media faculty and students (Darwish, 2017) found that both faculty and students agree on the necessity of including social media courses into the curricula of Arab media colleges, and using IT into the classrooms, the need of Arab Media institutions to have qualified faculty in social media. The study stated that most of Arab media faculty use traditional ways in teaching media courses, and Arab media students are not ready to be taught media courses by using social media as educational tool. 


\section{SOCIAL MEDIA EDUCATION IN ARAB MEDIA PROGRAMS}

Reviewing the literature and the curricula of Arab media programs reveal the following:

There is no separate program for social media in any Arab media programs in the Arab world. We analyzed the study plans of twenty-five Arab universities. All of them are not offering social media as an independent track. Most of them are not even offering courses under the title of social media, expect few of them such as Zayed university is offering a course titled introduction to social media, the American University in Sharjah is offering two courses: social media strategies and social media for mass communication, Bahrain university and Ahlia University are offering a course titled social media.

Few Arab media programs are starting to offer some related courses such as: new media, online journalism, computer assisted reporting and multimedia journalism which may provide the students with information related to social media. However, these courses do not focus on teaching social media, they are more interested in teaching media technology, graphics and multimedia, such as the program of communication in Sharjah University, Qatar University and Kind Saud University. In (2018) study, we found that only 67.1\% of Arab media educators and $72.4 \%$ of students said that there is no separate program for social media. They stated that few topics related to social media are embedded into some media courses. Only $35.5 \%$ of educators said social media is being integrated to a great extent into some courses.

There is a lack of interest in offering social media in most Arab media programs. Most Arab Media colleges still follow the same patterns of offering traditional tracks such as journalism, public relations, broadcasting. However, few programs are offering new tracks such as new media, integrated communication, visual communication, etc.

Our previous study showed that most Arab media faculty still use conventional online tools not the interactive such as social media in teaching their media courses. One way of communication is the most dominant way of interacting with students, such as sending an email or SMS, or just posting messages and announcements on social media. We found significant differences between faculty and students regarding the need of Arab media colleges to encourage using IT in the classrooms, including social media into their curricula, and teaching media courses through social media. A significant difference regarding the need of Arab Media institutions to have qualified faculty in social media and the need for special courses about social media was found between faculty and students. However, the new generations either of Arab media faculty or students are more willing to use social media in their educational process.

The use of social media is not noticeable to some extent, especially in academic matters. Only two thirds of Arab media faculty confirmed that social media is being integrated to a great extent into some courses. Several Arab media faculty and students still do not consider social media as an educational tool. Both faculty and students agreed on the lack of trust towards social media information. The students consider social media as a wasting time, not beneficial for media education, more than faculty, while faculty consider that social media distracts students in the classroom. The students said it represents an extra burden, and costs much.

Both Arab media faculty and students have positive attitudes towards the benefits of social media in creating online courses, delivering course materials, utilizing multimedia to make the course easier to comprehend, allowing shared information among students, encouraging shy students to participate, discovering the students' potentials, sending instant communication, enhancing students' skills in areas related to research, inciting interactive learning, improving faculty' technological skills, improving faculty' technological skills, fitting with media students' interests, enhancing social relationships, and students' communication skills.

On the other hand, both faculty and students did not agree on most negative aspects of social media such as; wasting time, spreading rumors, being an entertainment more than an educational tool, lacks of privacy, difficult to document its data, distracts students in the classrooms, not beneficial to media education.

Despite the widespread belief that social media reporting skills should be taught in collegiate classrooms, there is a lack of documentation and criticism of instructional experiences. Journalism and mass communication instructors are left wondering how they can best integrate social media into their existing curriculum. Previous research stated that there is a lack of literature that addresses the pedagogical approaches to integrating social media reporting into the media curricula. In addition, few practical guides written for journalism educators about how to incorporate social media in their courses are available; yet there is little understanding of how it works in practice for students beyond a few case studies. We know even less about how social media use in class effects journalism faculty. Few Arabic books have tackled the issue of social 
media and its impacts on media education. Most of them discussed the issue of new media and its approaches (Abbass Sadak, 2010) (Hosni Nasr, 2003) (Reda Amin, 2019).

Few Arab media journals and conferences have tackled social media as a field, most of them have addressed the impacts of social media (Mamdouh Shtlh and Hanan Kamel, JOMEM, 2015), evaluating social media (Elsayed Darwish, 2013), the practices, social media and Arab Spring (Davison, JOMEM, 2015). and the methodologies of social media (see Research Methods in New Media book, by Hossam Elhamy and others, 2014) and social media and its applications conference (Mohamed bin Saud University, 2015).

\section{OBSTACLES FACING SOCIAL MEDIA EDUCATION IN THE ARAB WORLD}

Table 1. Shows faculty and students' perceptions of topics to be included in social media courses

\begin{tabular}{|c|c|c|c|c|c|c|c|}
\hline Attitudes Towards SM use in education & Rank & $\mathrm{N}$ & Mean & $\mathrm{SD}$ & $\mathrm{t}$ & df & Sig. \\
\hline \multirow[t]{2}{*}{ Curricula of Arab media colleges do not include SM courses } & Teachers & 73 & 2.71 & .565 & \multirow[t]{2}{*}{1.785} & \multirow[t]{2}{*}{250} & \multirow[t]{2}{*}{.075} \\
\hline & Students & 179 & 2.55 & .671 & & & \\
\hline \multirow{2}{*}{$\begin{array}{l}\text { Offering SM courses in our universities required unavailable } \\
\text { equipment }\end{array}$} & Teachers & 73 & 2.05 & .896 & \multirow{2}{*}{1.785} & \multirow{2}{*}{250} & \multirow{2}{*}{.075} \\
\hline & Students & 179 & 2.13 & .757 & & & \\
\hline \multirow[t]{2}{*}{ No Arab qualified Media faculty to teach SM courses } & Teachers & 73 & 2.11 & .906 & \multirow[t]{2}{*}{.265} & \multirow[t]{2}{*}{249} & \multirow[t]{2}{*}{.791} \\
\hline & Students & 178 & 2.08 & .813 & & & \\
\hline \multirow[t]{2}{*}{ Media students consider SM courses not beneficial } & Teachers & 73 & 2.07 & .887 & \multirow[t]{2}{*}{1.252} & \multirow[t]{2}{*}{249} & \multirow[t]{2}{*}{.212} \\
\hline & Students & 178 & 1.93 & .781 & & & \\
\hline \multirow[t]{2}{*}{ Social Media does not require special courses } & Teachers & 73 & 1.70 & .845 & \multirow[t]{2}{*}{-3.767} & \multirow[t]{2}{*}{248} & \multirow[t]{2}{*}{.000} \\
\hline & Students & 177 & 2.11 & .768 & & & \\
\hline \multirow[t]{2}{*}{ Most Media courses should be taught through social media } & Teachers & 73 & 1.93 & .822 & \multirow[t]{2}{*}{-3.498} & \multirow[t]{2}{*}{248} & \multirow[t]{2}{*}{.001} \\
\hline & Students & 177 & 2.31 & .744 & & & \\
\hline \multirow{2}{*}{$\begin{array}{l}\text { Arab Media colleges should include social media into their } \\
\text { curriculums }\end{array}$} & Teachers & 61 & 2.67 & .598 & \multirow[t]{2}{*}{2.035} & \multirow[t]{2}{*}{175} & \multirow[t]{2}{*}{.043} \\
\hline & Students & 116 & 2.46 & .703 & & & \\
\hline \multirow{2}{*}{$\begin{array}{l}\text { Arab Media colleges should encourage using IT in the } \\
\text { classrooms }\end{array}$} & Teachers & 61 & 2.80 & .477 & \multirow[t]{2}{*}{2.010} & \multirow[t]{2}{*}{173} & \multirow[t]{2}{*}{.046} \\
\hline & Students & 114 & 2.63 & .569 & & & \\
\hline \multirow[t]{2}{*}{ Most Arab media faculty use traditional ways in teaching } & Teachers & 61 & 2.61 & .665 & \multirow[t]{2}{*}{1.119} & 173 & .265 \\
\hline & Students & 114 & 2.49 & .641 & & & \\
\hline Arab media students are not ready to be taught through SM & Teachers & 61 & 1.77 & .864 & -.624 & 172 & .533 \\
\hline & Students & 113 & 1.85 & .759 & & & \\
\hline Assignments should be submitted it through SM & Teachers & 73 & 2.59 & .642 & 2.559 & 242 & .011 \\
\hline & Students & 171 & 2.34 & .721 & & & \\
\hline
\end{tabular}

Media programs in Arab Universities are facing many obstacles which hinder their efforts to integrate social media into their programs such as:

- The dominance of conventional curricula on the current pedagogy, teaching and research in most programs which follow a traditional division of offering media and communication programs.

- There are shortcomings of faculty who are qualified to use technology and able to integrate social media into their courses.

- Most of Arab universities' infrastructure are not ready to offer programs based on technology and social media. In addition to the lack of access to information, the instability of the region, some states restrictions on social media, the social, religious, cultural taboos which prevent social media from flourishing. This results in the whole process of social media reporting being a tedious and challenging exercise, with the dominance of entertainment culture rather than reporting culture among social media users. This is in the addition to the cost of smartphones, the absence of $4 \mathrm{G}$ internet connection and the shortage of skilled people in social media sector.

- There are some negative perceptions of social media as an educational tool among Arab media faculty; some consider it as a communication and entertaining tool. Our study found that Arab media students are using IT facilities than faculty. Students are using chatting and sharing materials more than posting or commenting on social media. They are interested in using social media in communication, more than 
creating content on social media. They prefer using email, mobile and the internet in general over using social media. Most Arab media faculty use traditional ways in teaching. Both faculty and students agree that Arab Media institutions need to have qualified faculty in social media. While faculty agreed that the assignments should be submitted through social media, the students did not agree. (T-test=.011). We found significant differences between faculty and students regarding the need for Arab media colleges to encourage using IT in the classrooms, including social media into their curricula, teaching media courses through social media, and submitting assignments.

- Our study found that both Arab media faculty and students agree on the necessity of including social media courses into the curricula of Arab media colleges and using IT into the classrooms. Significant differences between faculty and students regarding integrating issues related to social media management, marketing by social media, and advertising on social media. However, they agree on integrating other issues into media courses such as: publishing news on social media, ethics of communication through social media, social media campaigns, mobilization of public opinion through social media, and utilizing multimedia in social media.

- Most of Arab students and faculty use social media for general purposes not educational, which limit their abilities to propose perspectives on the ways which social media can be used in media education and their perceptions of social media. Our previous study showed that the students are interested in using social media in communication, more than creating content on social media. They also did not agree on some positive aspects such as: social media gathers all parties in one platform, and reduces the cost of education, time assigned for assignments and the rate of absence. (Darwish, 2018).

- Nowadays, social media is witnessing a lot of debates regarding its credibility, its role in spreading hate, crimes, discrimination and fake news, which affects its ability to be used as trusted educational tool.

- There is an absence of code of ethics for social media use either among most Arab Universities or Arab media organizations which have negative impacts on its use.

- The political interventions in some Arab countries in the use of social media hinder the free use of social media.

- There is lack of literature related to social media education, and absence of guidelines of how to use it into media classrooms.

There is a communication gap between Arab media colleges and Arab media organizations and other related communication institutions in terms of coordinating their efforts to help them graduate competent students in social media and provide them enough training.

\section{MEDIA ORGANIZATIONS AND THE NEEDED SKILLS OF SOCIAL MEDIA}

The debate over whether social media is overwhelmingly positive or negative for journalism and mass media is paralleled in a debate over the inclusion of social media in classrooms, which focus on to what extent media colleges have sufficient infrastructure to offer social media programs, to what extent media faculty are competent or willing to teach social media courses or integrate it into their courses and what are the best ways to help media students become competent in acquiring the conventional media skills and digital skills.

Incorporation of social media tools into professional media routines has increased, although unevenly and at varied paces, over the last years. It has evolved to the point that many news organizations publish social media guidelines and offer training (Jordaan, 2013) (Kothari and Hickerson, (2016).

However, the approaches of distinct media organizations have varied considerably, in terms of their capacity to embrace multiplatform journalism and multimedia convergence, thus making it difficult to identify uniform skills needed for success, consequently, put more pressures on media researchers and educators to figure out the best way to cope with changing needed skills and re-evaluate media education to meet digital demand in the news media business (Bor, 2014)

Although students reported that they had experience using social media, they felt inadequate in their ability to use the technology in a professional capacity and as a medium for producing news. Hirst and Treadwell concluded that social media "must form part of the content of lectures, seminars, and workshops; the tools and techniques that empower digital story-telling are now essential learning for our graduates." (Hirst and Treadwell, 2011) (Bor, 2014). Similarly, Wenger and Owens agreed that educators should improve 
their efforts to prepare students for social media jobs by helping them understand how this medium can be utilized as a newsgathering and dissemination tool (Wenger and Owens, 2010) (Bor, 2014). Knowledge of social media and convergence reporting skills gives journalists opportunities to enhance their stories by giving them the tools to convey news in the most appropriate medium, while also making them more marketable to future employers (Bor, 2014).

In Arab media organizations, it is evident that the culture and practices of social media in Arab world are facing many challenges. The discussions with some Arab media educators and media elites showed that most Arab media organizations are not ready to integrate social media into their own newsrooms, which is due to their financial problems, and having unequipped journalists with insufficient technological skills to adapt the practices of social media reporting. They stated that there is a conflict between the traditionalists and innovative journalists regarding the use of social media and utilize it as a source of information and news. Some of them stated that most of social media reporting lack the standards of professionalism and technicality which prevent them from running its information and news through their platforms. They also stated that there is an absence of media literacy among users, absence of a revenue model for social media in the Arab world, an unwillingness of media organizations to adapt users generated reporting into their own stream products.

\section{THE NEED FOR SOCIAL MEDIA EDUCATION}

Initiating a new program for social media in Arab universities is a must for many reasons:

- Recent research finds that social media affects the audience's political culture and knowledge about every life aspect. Therefore, we need to offer students a scientific understanding and a deep knowledge of social media posts, hits, followers, and how to engage audience to actively, participate in community events and encourage them to learn usage of social media in branding and marketing and return of investment.

- It adds a needed track to the conventional tracks of media education, in a time where conventional media and Arab media programs are facing several threats and financial problems.

- There is a real need for social media track, to convince students to be enrolled in communication colleges, and to reduce the number of students who are dropping from media programs.

- It provides a new path for teaching digital skills for students and meets the need of news organizations.

- It paves the way for media convergence, providing students with more opportunities to find a job in a market which demands students who are competent in using social media.

- social media deserves to have its own major, since it includes several courses.

- Media students are required to be competent in social media; such as ethics of social media, social media marketing, writing for social media, etc.

- Social media program is an opportunity for journalists, media and communication, public relations practitioners and many more to learn the needed skills in our digital world.

- All government communication entities in the Arab region are mainly depending on social media. Most of their practitioners are seeking an opportunity to improve their skills and knowledge in the social media field.

- There is a huge need for alternative programs of communication programs, which are different from the conventional programs (journalism, public relations, broadcasting).

- Most of Arab media colleges need to reconstruct their curricula and offer new tracks.

- It is a new and needed specialization in the Arab region. It responds to a real and huge demand from Arab students for a specialized program in new and social media. Many Arab students have been forced to study abroad for the lack of media programs offered in their own countries.

\section{PROPOSING A PROGRAM FOR SOCIAL MEDIA EDUCATION}

The main question which has not been addressed yet is whether a separate track for social media is essential to be added to communication programs, beside journalism, broadcasting and public relations or they can just integrate it into the conventional media courses as units or as instructional tool, not as full and inclusive courses.

We think that it is the time to offer social media as a new track among other tracks in Arab media colleges, in addition to integrating social media into other courses and use it as educational tool. It should be built based on a holistic and integrated view of social media education. 
Arab media colleges should re-evaluate their media programs to meet the digital demand in the news media business and to improve the quality of teaching media courses.

Our study showed that both faculty and students agreed on the need of including social media into media curricula and having qualified faculty in social media.

There is also a need for theorizing the use social media in education in general, and in mass media in particular. These efforts should focus on the best ways of using social media, how can we use it, how can we integrate it into media curricula, the best practices of using social media in teaching media courses etc. in the same time, there is also a need for authorizing guidelines for using social media and fully examining some case studies.

These programs should seek to prepare a generation of Arab students to deal with new and social media theoretically and practically by offering an integrated and excellent program in new and social media fields. It should focus on both the social media applications themselves and the issues surrounding their use by journalists. In addition to Forming social media as a part of the content of lectures, seminars and workshops; the tools and techniques that empower digital story-telling which are now essential learning for our graduates.

It is important for instruction to emphasize on differences in using social media for personal versus professional use, emphasize on effective social media writing and editing, include technical instruction on how to proficiently use social media platforms, with "leveraging the digital media habits" of tech-savvy students and emphasize on ethics, technical skills, and the potential for career development. They also should supplement classroom experiences via email, blogs and bulletin boards; online searching and evaluation of sources; online assessments; multimedia and podcasting; digital archives, course websites, emailed assignments and online discussions.

The program should be built on an integrated content in terms of its courses; combine between writing, production, planning, and research whilst providing the students with the required knowledge and skills to study and work professionally in the new and social media outlets.

These programs should deal with the communication, historical, technical, economic, cultural, and legal aspects of social media, in addition to the impacts, and uses of social media in news, media, communication, marketing, public relations, advertising and how we can measure and analyses its performance digitally.

Social media programs should aim at enabling students: (1) understand social media technologies and their best optimum usage. (2) design and implement an effective communication strategies and social media campaigns for a target audience. (3) write and produce online materials for social media (4) analyze social media audiences, and marketing opportunities (4) measure and track ROI of social media campaign. (5) acquire the critical awareness of social media uses, issues, methodologies, the latest developments in social media impacts, measurement, skills, techniques, analysis, research methods, audiences in digital era, online governance and marketing, interactive media, social media ethics and laws, government communication, social media management and business models. (6) apply social media practices and knowledge to different media platforms, (7) understand the technological, ethical and legal aspects of social media. (8) engage in research practices on social media issues, approaches, uses and impacts on societies. (9) administrate social media pages and utilize them for communication, branding and marketing purposes.

The program should combine the theoretical study and the practical applications. Students should utilize their research and knowledge skills in planning and producing media and marketing campaigns using social media.

The program should target not only media students, but also other students from different major, to study it as a minor, especially students from the above colleges and others, who are intending to work in social media, marketing, branding, tourism fields, etc.

These programs should prepare its graduates to be researchers in the above fields and editors of social media and online portals

These programs should provide students with an opportunity to be recruited in media organizations, new and social media portals, and in public relations, marketing and advertising entities.

These programs can include the following courses: (1) social and new media theatrical approaches (2) online writing for new media (3) social media production (4) campaigns Planning \& production $\&$ marketing through social media (5) research methods for social and new media(6) business models for social and new media (7) Law and ethics for social media (8) social media Analytics \& measurements (9) government social media communication (10) data and mobile journalism. it can also offer a range of courses related to different fields like new media, social media campaigns \& analytics \& measurements, writing \& production, 
e-advertising and E-Marketing with concentration on Gulf region and Arab countries audience, media, law and ethics.

In sum, Arab media educators are encouraged to improve their IT skills, find ways to integrate social media into their courses and challenge the bureaucratic inertia and resource constraints which hinder their efforts to cope with the need of media business.

\section{REFERENCES}

Ammina Kothari and Andrea Hickerson. (2016). Social Media Use in Journalism Education: Faculty and Student Expectations, Journalism \& Mass Communication Educator, 2016, Vol. 71(4) 413-424.

Auxier, B. E. (2012). Social media instruction in journalism and mass communications higher education (Master's thesis). University of Maryland, College Park.

Deb Halpern Wenger and Lynn C. Owens, "Help Wanted 2010: An Examination of New Media Skills Required by Top U.S. News Companies," Journalism \& Mass Communication Educator 67, no. 1 (2012): 9-25.

Darwish, B. Elsayed, 2015, The Political Roles of Social Media Networks in the Arab World: Indicators Assessment and a Proposed Model. Journal of Middle East Media, Vol.9.

Darwish, B. Elsayed (2016). The theoretical and methodological issues of social media, Journal of Mass Communication Research. Vol 16. Nov 2016.

Darwish, B. Elsayed (2017). The Effectiveness of Using Social Media in Government Communication in UAE. Journal of Arab \& Muslim Media Research., Vol. 10 Issue 1, p41-63.

Darwish, B. Elsayed (2018). Arab media faculty and students' attitudes towards using social media in Education. Journal of Mass Communication Research Vol.19, pp 278-330.

Guy, Retta (2012). The Use of Social Media for Academic Practice. Kentucky Journal of Higher Education Policy and Practice: Vol. 1 : Iss. 2 , Article 7. Available at: http://uknowledge.uky.edu/kjhepp/vol1/iss2/7.

Hirst, M., \& Treadwell, G. (2011). Blogs bother me: Social media, journalism students and the curriculum. Journalism Practice, 5, 446-461.

Jackson, L., Ervin, K., Gardner, P., \& Schmitt, N. (2001). The racial digital divide: Motivational, affective, and cognitive correlates of Internet use. Journal of Applied Social Psychology, 31(10), 2019-2046.

Junco, R., Heibergert, G. \& Loken, E. (2011). The effect of Twitter on college student engagement and grades. Journal of Computer Assisted Learning, 27, 119- 132.

Jordaan, M. (2013). Poke me, I'm a journalist: The impact of Facebook and Twitter on newsroom routines and cultures at two South African weeklies. Ecquid Novi: African Journalism Studies, 34, 21-35.

Junco, R., Heiberger, G., \& Loken, E. (2011). The effect of Twitter on college student engagement and grades. Journal of Computer Assisted Learning, 27, 119-132.

Lasorsa, D. L., Lewis, S. C., \& Holton, A. E. (2012). Normalizing Twitter: Journalism practice in an emerging communication space. Journalism Studies, 13(1), 19-36.

Martin Hirst and Greg Treadwell, "Blogs Bother Me: Social Media, Journalism Students and the Curriculum,” Journalism Practice 5 (2011): 446-61.

Paula Hodgson and Dora Wong, "Developing Professional Skills in Journalism through Blogs," Assessment \& Evaluation in Higher Education 36 (March 2011): 197-211.

Poellhuber, B. \& Anderson, T. (2011). Distance students' readiness for social media and collaboration. The International Review of Research in Open and Distance Learning, 12(6), 102-125.

Roger Cooper and Tang Tang, "The Attributes for Career Success in the Mass Communication Industry: A Comparison of Current and Aspiring Professionals," Journalism \& Mass Communication Educator 65 (spring 2010):40-55.

Stephanie E. Bor (2014) Teaching Social Media Journalism: Challenges and Opportunities for Future Curriculum Design, Journalism \& Mass Communication Educator 2014, Vol. 69(3) 243- 255

Veletsianos, G. (2012). Higher education scholars' participation and practices on Twitter. Journal of Computer Assisted Learning, 28, 336-349. 